\title{
ИНВЕСТИЦИИ И ИХ РОЛЬ В ЭКОНОМИКЕ РЕГИОНА
}

\section{Петина Полина Владимировна ${ }^{1}$}

Самарский национальный исследовательский университет имени академика С.П. Королева, г. Самара

Аннотация: Статья посвящена исследованию роли инвестиций в экономике региона, в частности Самарской области. Проведен анализ инвестиционной привлекательности Самарской области для определения «слабых мест» и обозначения приоритетных направлений деятельности в будущем.

Ключевые слова: инвестиции, инвестиционный климат, функции инвестиций, инвестиционная деятельность.

Неотъемлемой и очень важной частью развития региона являются инвестиции. Инвестиции - это тот инструмент, без которого невозможно представить какой-либо экономический рост. Региональные инвестиции представляют собой общее количество затрат всех субъектов предпринимательской деятельности, управленческих структур и населения региона, направленных на долгосрочные капиталовложения в отдельно взятые отрасли экономической деятельности в определённом регионе.

Инвестиционная деятельность предусматривает некоторые цели:

1. Создание и поддержание надёжной финансовой базы региона

2. Решение социальных проблем

3. Повышение экономической и хозяйственной самостоятельности региона

4. Улучшение положения государства в целом

5. Выравнивание социально-экономической дифференциации между регионами

Чтобы добиться эффективного результата, необходимо построить инвестиционную стратегию, так как первоочерёдным должен быть план, а не действия. Инвестиционная стратегия представляет собой систему разносрочных целей инвестиционной деятельности, то есть это программа непосредственно вложения ресурсов в определенную сферу.

Нельзя не подчеркнуть актуальность проблемы инвестиций в современном мире, рынок активно развивается и требует качественных вложений.

Следует понять, как работает процесс вовлечения инвестиций в тот или иной регион. Процесс привлечения инвестиций является одним из самых проблемных в наше время. Главным фактором привлечения инвестиций в регион

\footnotetext{
${ }^{1}$ Студент 4 курса бакалавриата Института экономики и управления Самарского университета. Научный руководитель: Манукян М.М., кандидат экономических наук, старший преподаватель кафедры экономики инноваций Самарского университета.
} 
является его инвестиционная привлекательность, что требует от властей обеспечения благоприятных условий, способствующих привлечению и увеличению эффективности использования данных ресурсов.

Изучение инвестиционного климата также является серьёзным шагом в процессе получения инвестирования, оценка климата представляет собой процесс определения тенденций, которые способны влиять на инвестиционную деятельность. Составляющие инвестиционного климата можно охарактеризовать тесным взаимодействием и взаимовлиянием. На рисунке указаны некоторые из этих составляющих (рисунок 1.)

\section{Инвестиционный климат - условия для среднесрочного или долгосрочного вложения капитала в различные отрасли данной страны или региона}

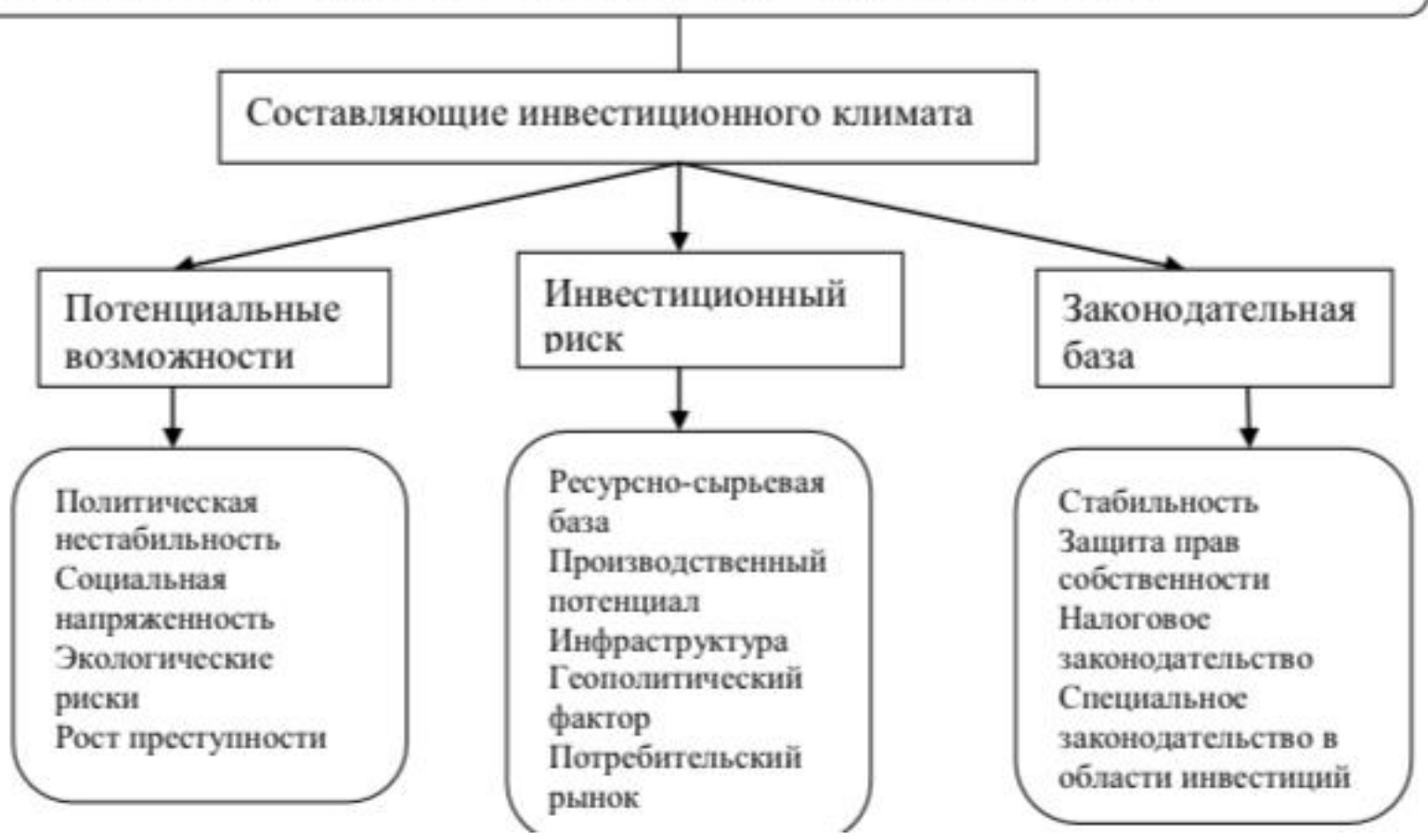

Рисунок 1 - Классификация составляющих инвестиционного климата страны

Рассмотрим более подробно проблему инвестиционной привлекательности региона на примере Самарской области. В Самарской области, особенно в последнее время, продвигается значимость инвестиционной привлекательности региона, власти создают максимально комфортную инвестиционную среду, законодательство гарантирует равные условия для каждого инвестора, а также способствует преодолению административных барьеров.

За последние годы инвестиционный ландшафт Самарской области совершенной изменился, проведена огромная работа по улучшению привлекательности региона. Регион в 2019 году добился огромных результатов, в рейтинге инвестиционного климата поднялся с 48 места на 24-е. 
Так как такое понятие как инвестиционный климат характеризуется двумя параметрами - инвестиционным риском и инвестиционным потенциалом, рассмотрим, что представляют из себя эти два параметра в Самарской области.

Если говорить об инвестиционном потенциале, то этот параметр в регионе более чем качественный, присутствует огромный инвестиционный потенциал, иностранные инвесторы заинтересованы во вложении денег в отдельные сферы области. Заключены соглашения о сотрудничестве с провинциями Канады, КНР, Венгерской республики, Индии, Болгарии, Чехии, Бразилии, Китая, Польши.

Преимущества Самарской области в плане инвестиционной привлекательности:

1. Диверсифицированная экономика

2. Благоприятный кластерный портфель

3. Высокий уровень урбанизации населения, привлекательность региона для трудовой миграции

4. Выгодное географическое положение

5. Наличие полезных ископаемых (углеводородное и минеральное сырье)

6. Благоприятные природно-климатические условия и наличие рекреационных ресурсов

7. Благоприятный деловой климат

Самарская область - регион с множеством возможных направлений для инвестирования.

Объекты инвестирования Самарской области:

1. Автомобилестроение

2. Нефтехимическая промышленность

3. Аэрокосмическая промышленность

4. Электротехническое оборудование и машиностроение

5. Сельское хозяйство

6. Медицинские технологии

Хоть положение области в плане инвестиционной привлекательности и укрепляется, необходимо рассмотреть проблемы, которые существуют и сейчас.

Выделим некоторые из них:

1. Поток прямых иностранных инвестиций довольно нестабилен

2. Высокий уровень административных барьеров, которых с каждым годом становится всё меньше

3. Коррупция, которая является косвенным следствие высокого уровня административных барьеров 
Для решения существующих проблем необходимо прибегнуть к основным принципам инвестиционной политики Самарской области (рисунок 2).

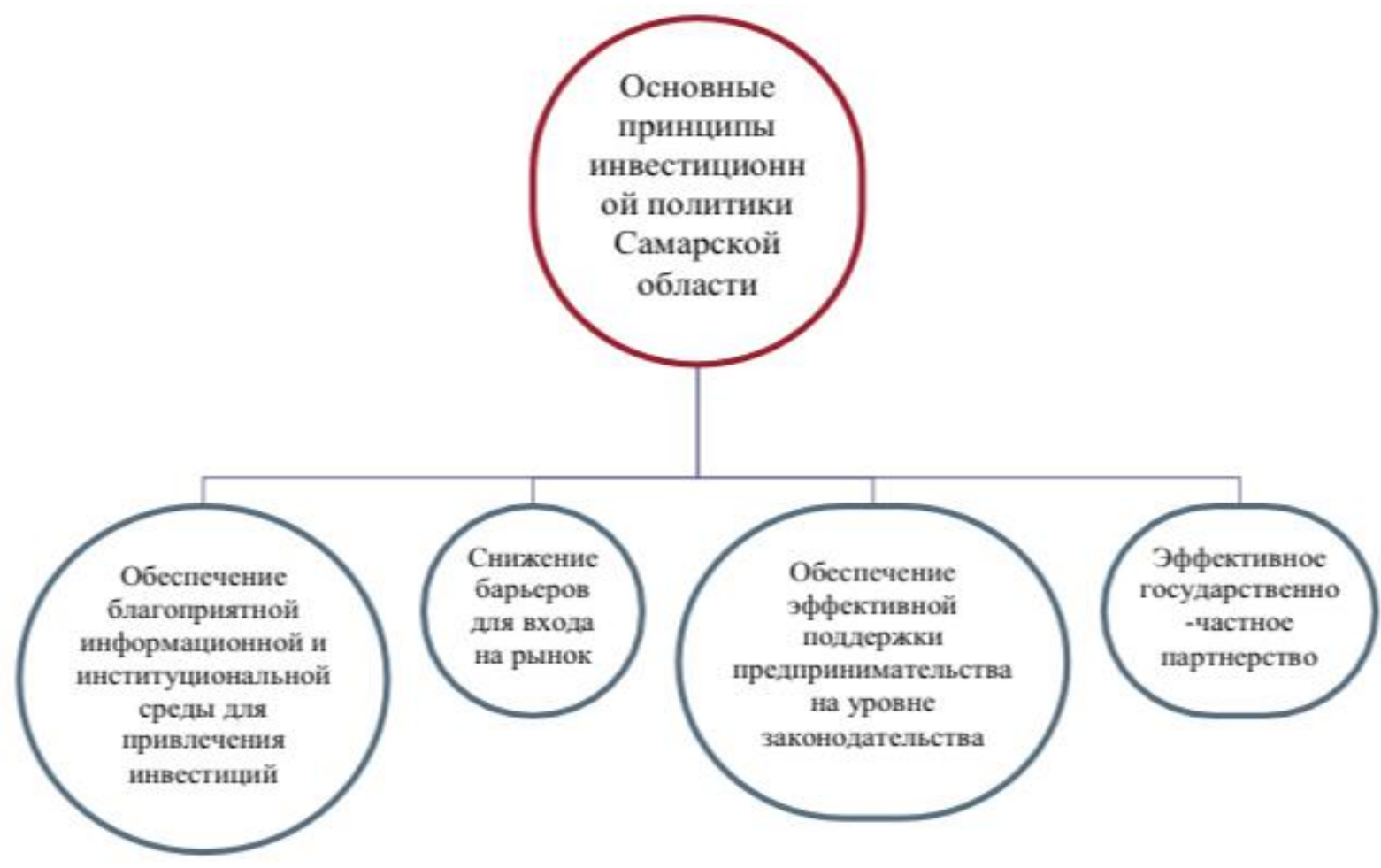

Рисунок 2 - Основные принципы инвестиционной политики Самарской области

В настоящее время область движется в правильном направлении, необходимо поддерживать заданный курс и не отходить от намеченного плана.

\section{Список использованных источников:}

1. Вершинина А.А. Прямые иностранные инвестиции и особенности их привлечения в экономику страны и региона// Экономика, статистика и информатика, - 2013, - № 3.

2. Территориальный орган Федеральной службы государственной статистики по Самарской области «Самарастат». Режим доступа: http://samarastat.gks.ru/ (дата обращения 29.11.2019) 